\title{
социология
}

DOI: $10.17805 / G G Z .2017 .5 .7$

\section{Адаптация к учебе в вузе отдельных проблемных групп первокурсников: эмпирические данные и теоретические выводы}

\author{
ВАЛ. А. ЛУКОВ, С. В. ЛУКОВ \\ МОСКОВСКИЙ ГУМАНИТАРНЫЙ УНИВЕРСИТЕТ
}

Опираясь на фрагмент ежегодного исследования по первокурсникам Московского гуманитарного университета, относящийся к выделению проблемных групп, испытывающих трудности в адаптации к учебе в гуманитарном вузе, авторы статьи показывают, как эмпирические данные формируют теоретические представления в области социологии молодежи.

Ключевые слова: социология молодежи; тезаурусный подход; первокурсники; трудности адаптации в вузе; современные проблемы обучения

\section{Adaptation to education of individual problem groups of freshmen: empirical data and theoretical results \\ VALERY A. LUKOV, SERGEY V. LUKOV \\ MOSCOW UNIVERSITY FOR THE HUMANITIES}

Based on a fragment of the annual survey on first-year students of Moscow University for the Humanities pertaining to the allocation of problem groups who have difficulties in adapting to their studies, the article shows how empirical data form theoretical concepts in the field of sociology of youth.

Keywords: sociology of youth; thesaurus approach; freshmen; adjustment difficulties in high school; modern problems of education

\section{ВВЕАЕНИЕ}

Выявление проблемных групп первокурсников гуманитарных вузов для самих этих вузов представляет чисто практическую задачу. Если такие группы выявлены, на их проблемах могут сосредоточиться администрация, кураторы, преподаватели, сюда может быть привлечено студенческое самоуправление и т. А. Но есть и теоретическая часть этой задачи, она состоит в том, что проблемные группы первокурсников не возникают как чисто психологический феномен, они опосредованно отражают определенную напряженность в обществе, которая или уже существует, или только готова возникнуть в неопределенной перспективе. Само исследование первокурсников в известной мере это исследование будущего, поскольку проведенное в начале образовательного процесса в вузе (например, в сентябре-октябре), оно ничего не говорит о воздействии вуза на новое поколение студентов в области обучения и воспитания, 
если не считать важными их ожидания от вуза и будущей профессии (на самом деле, это существенная информация и в практическом, и в теоретическом плане).

В Московском гуманитарном университете исследование первокурсников проводится с 2004 г. (Первокурсник..., 2005аb). Первоначально это была часть исследования всех студентов (панельные исследования велись одновременно на первом, третьем и выпускном курсах по одной и той же методике). Потом исследование первокурсников выделилось в отдельный мониторинг, который проводится ежегодно в начале учебного года (Гневашева, 2008; Ауков и др., 2006; Ауков, 2015а). Используется сплошной опрос, что позволяет иметь информацию от 70-90\% студентов, пришедших в вуз на все имеющиеся формы обучения.

В настоящей статье адаптация к учебе в вузе рассматривается только в аспекте выявления и кластеризации проблемных групп (по материалам отчета за 2010 г.), но полученные эмпирические данные показывают, что исследование предполагает и теоретические выводы, на которых авторы и считают важным сосредоточиться.

\section{ПРОБАЕМНЫЕ ГРУППЫ}

По некоторым показателям могут быть выделены группы первокурсников, которые могут хуже адаптироваться к обучению в гуманитарном вузе, чем в среднем по контингенту поступивших на первый курс. Эти группы не являются реальными, они выявляются только аналитически, тем не менее они заслуживают внимания.

Первокурсники, характеризующие свое жизненное настроение как напряженное (Группа A). Отвечая на вопрос «Что бы Вы могли сказать о своем жизненном настроении?», 6,1\% первокурсников выбрали позицию «испытываю напряжение, раздражение», $0,9 \%$ - «испытываю страх, тоску», 9,6\% затруднились с ответом, т. е. не выбрали предложенных позиций с позитивным содержанием. Эти три варианта ответов, таким образом, характеризуют достаточно большую группу опрошенных, составляющих 16,5\%. В исследовании она обозначена как «Группа А». По самооценкам своего материального положения эта группа не выделяется на фоне средних показателей. В ней несколько больше представлены проживающие в общежитии $(21,1$ против $15,7 \%$ в среднем) и на съемных квартирах (10,5 против $4,3 \%)$, однако субъективная оценка жизненного настроения оказывается, видимо, более значимым свидетельством готовности/неготовности к жизненным трудностям.

Выделенная по этому основанию Группа А характеризуется ослабленной направленностью интереса $x$ выбору вуза (вдвое больше, чем в среднем, ответов «легче всего было поступить» и «увидел привлекательную рекламу университета»), планированию последующей профессиональной карьеры, самовлюбленностью и т. д. Здесь наибольшая доля тех, кто пришел в вуз, чтобы «получить диплом» $(52,6 \%$ при среднем $42,4 \%$ и $34,9 \%$ у тех, кто отмечает свое «прекрасное» жизненное настроение) и наибольшая доля тех, кто выбрал ответ «не знаю, мне все равно» (5,3\% на фоне 1,7\% в среднем по опрошенным первокурсникам и отсутствием такого ответа среди тех, у кого «прекрасное» настроение), зато ослаблен импульс даже для планов иметь высокую зарплату после окончания вуза (47,4\% по Группе А против $61,9 \%$ в среднем). Это общее состояние расслабленности заметно и по другим ответам. Характерно, что в Группе А почти две трети $(57,9 \%)$ не смогли сформулировать своего отношения к тому, является ли сегодня высшее образование гарантией жизненного успеха, что вдвое больше, чем среди отметивших свое «прекрасное» жизненное настроение и «нормальное, ровное состояние» $(27,9$ и $26,4 \%)$. В том же ключе может рассматри- 
ваться реже выражаемое в Группе А намерение впоследствии работать по специальности, полученной в МосГУ (31,6\% при среднем 48,3\%, в группе с «прекрасным» настроением - 51,2\%).

По вопросам анкеты можно реконструировать некоторые доминанты в ценностных ориентациях и мотивах поведения данной группы (таблица 18).

ОТВЕТЫ НА ВОПРОСЫ АНКЕТЫ ПЕРВОКУРСНИКОВ,

Таблииа 18

ОЦЕНИВШИХ СВОЕ ЖИЗНЕННОЕ НАСТРОЕНИЕ КАК НАПРЯЖЕННОЕ (ГРУППА А, в \%)

\begin{tabular}{|c|c|c|}
\hline $\begin{array}{l}\text { Bопросы анкеть } \\
\text { и Варианты ответов }\end{array}$ & Групnа A & $\begin{array}{c}\text { Средний } \\
\text { показатель }\end{array}$ \\
\hline \multicolumn{3}{|c|}{ На выбор Вами нашего университета В большей степени повлияло то, ито... } \\
\hline $\begin{array}{l}\text { университет расположен близко к моему дому } \\
\text { увидел (а) привлекательную рекламу университета } \\
\text { (в Интернете, на улице и т. А.) } \\
\text { легче всего было поступить }\end{array}$ & $\begin{array}{l}21,1 \\
26,3 \\
26,3\end{array}$ & $\begin{array}{l}40,5 \\
12,1 \\
11,2\end{array}$ \\
\hline \multicolumn{3}{|c|}{ Каковы Ваши планы после окончания университета? } \\
\hline $\begin{array}{l}\text { работать по специальности, полученной в МосГУ } \\
\text { найти высокооплачиваемую работу, даже если она будет } \\
\text { не по специальности } \\
\text { уехать на работу за границу }\end{array}$ & $\begin{array}{l}31,6 \\
42,1 \\
36,1\end{array}$ & $\begin{array}{l}48,3 \\
33,1 \\
23,7\end{array}$ \\
\hline \multicolumn{3}{|c|}{ Что, по Вашему мнению, означает «хорочо жить»? } \\
\hline $\begin{array}{l}\text { быть материально обеспеченным } \\
\text { иметь хорошую семью, детей } \\
\text { любить и быть любимым } \\
\text { быть здоровым }\end{array}$ & $\begin{array}{l}73,7 \\
63,2 \\
68,4 \\
63,2\end{array}$ & $\begin{array}{l}70,9 \\
75,2 \\
58,1 \\
53,8\end{array}$ \\
\hline \multicolumn{3}{|c|}{$\begin{array}{l}\text { Tот (та), на кого Вы хотели бы походить, } \\
\text { на кого ориентируетесь в своей жизни, - что он (она)? }\end{array}$} \\
\hline на самого себя & 21,4 & 15,1 \\
\hline \multicolumn{3}{|c|}{ Чего Bы опасаетесь больше Всего? } \\
\hline $\begin{array}{l}\text { ухудшения материального положения (своего, своей семьи) } \\
\text { одиночества } \\
\text { нападения грабителей, бандитов } \\
\text { предательства друзей } \\
\text { неясного будущего }\end{array}$ & $\begin{array}{l}42,1 \\
57,9 \\
21,1 \\
31,6 \\
31,6\end{array}$ & $\begin{array}{l}39,8 \\
43,4 \\
12,4 \\
26,5 \\
21,2\end{array}$ \\
\hline \multicolumn{3}{|c|}{ Что Вас больше всего настораживает в учебе и студенческой жизни на территории МосГУ } \\
\hline финансовые трудности оплаты обучения на следующих курсах & 31,6 & 14,7 \\
\hline \multicolumn{3}{|c|}{$\begin{array}{c}\text { Oтметьте трудности, с которыми Вам уже пришлось столкнутьсл } \\
\text { в прочессе обучения в университете: }\end{array}$} \\
\hline материал на занятиях излагается преподавателем непонятно & 16,7 & 8,9 \\
\hline \multicolumn{3}{|c|}{ Кто помогает Вам решать возникаюшие в процессе обучения проблемы? } \\
\hline решаю сам(a) & 63,2 & 50,4 \\
\hline
\end{tabular}


Эгоистическая направленность Группы А и мрачное восприятие жизни может создавать сложности при формировании студенческих коллективов, ориентированных на достижения в учебе и будущий карьерный рост.

Первокурсники, предполагающие после окончания университета найти высокооплачиваемую работу не по специальности (Группа Б). Группа Б выделена в исследовании по ответу на вопрос «Каковы Ваши планы после окончания университета?», отражающему намерение части первокурсников «найти высокооплачиваемую работу, даже если она будет не по специальности». Таких в составе опрошенных оказалось $33,1 \%$. Специфика такого жизненного плана стоит в том, что высшее образование выступает лишь необходимой формальностью для доступа к жизненным благам, интерес к профессиональному росту на базе высшего образования хоть и не отсутствует, но смазан, находится на периферии жизненных интересов. Некоторые характеристики Группы Б. представлены в таблице 19.

Таблииа 19

ОТВЕТЫ НА ВОПРОСЫ АНКЕТЫ ПЕРВОКУРСНИКОВ, ВЫСКАЗАВШИХ МНЕНИЕ ЧТО ПОСАЕ ОКОНЧАНИЯ ВУЗА ХОТЕАИ БЫ НАЙТИ ВЫСОКООП АЧИВАЕМУЮ РАБОТУ, ААЖЕ ЕСАИ ОНА БУАЕТ НЕ ПО СПЕЦИААЬНОСТИ (ГРУППА Б, В \%)

\begin{tabular}{|c|c|c|}
\hline $\begin{array}{c}\text { Bonpocь } \\
\text { u варианты ответов }\end{array}$ & Групnа Б & $\begin{array}{c}\text { Средний } \\
\text { показатель }\end{array}$ \\
\hline \multicolumn{3}{|c|}{ Что, по Вашему мнению, означает «хорошо жить»? } \\
\hline $\begin{array}{l}\text { быть материально обеспеченным } \\
\text { иметь хорошую работу } \\
\text { иметь хорошую семью, детей } \\
\text { любить и быть любимым } \\
\text { быть здоровым } \\
\text { иметь друзей }\end{array}$ & $\begin{array}{l}78,9 \\
55,3 \\
76,3 \\
47,4 \\
68,4 \\
34,2\end{array}$ & $\begin{array}{l}70,9 \\
47,9 \\
75,2 \\
58,1 \\
53,8 \\
38,5\end{array}$ \\
\hline \multicolumn{3}{|c|}{ На Вьбор Вами нашего университета В большей степени повлияло то, ито... } \\
\hline $\begin{array}{l}\text { здесь дают хорошее образование } \\
\text { университет расположен близко к моему дому } \\
\text { здесь умеренная плата за обучение } \\
\text { этот университет представляет возможности трудоустройства }\end{array}$ & $\begin{array}{l}64,9 \\
48,7 \\
32,4 \\
21,6\end{array}$ & $\begin{array}{l}49,1 \\
40,5 \\
18,1 \\
13,8\end{array}$ \\
\hline \multicolumn{3}{|c|}{ Чего Вь опасаетесь больше Всего? } \\
\hline $\begin{array}{l}\text { ухудшения материального положения (своего, своей семьи) } \\
\text { одиночества } \\
\text { болезней (своих или кого-то из близких) } \\
\text { измены любимого, любимой } \\
\text { потери близкого человека } \\
\text { предательства друзей }\end{array}$ & $\begin{array}{l}50,00 \\
50,00 \\
57,89 \\
23,68 \\
57,89 \\
42,11\end{array}$ & $\begin{array}{l}39,8 \\
43,4 \\
51,3 \\
17,7 \\
70,8 \\
26,5\end{array}$ \\
\hline \multicolumn{3}{|c|}{ Что Вас больше всего настораживает в учебе и студенческой жизни на территории МосГУ? } \\
\hline предстоящие экзамены, зачеты & 75,68 & 71,6 \\
\hline
\end{tabular}

«Хорошая жизнь»в преставлении рассматриваемой группы преимущественно ассоциируется со следующими позициями: «материальная обеспеченность», «хорошая семья», «здоровье». По этим позициям показатели Группы Б выше, чем средние по 
контингенту первокурсников, к ним прибавляется ценностная ориентация, выражаемая формулой «иметь хорошую работу», присущая больше чем половине отнесенных к этой группе в рамках анализа данных.

В Группе Б ряд позиций создает благоприятные возможности для адаптации к условиям учебы в гуманитарном вузе. В частности, здесь больше позитивных оценок такого вуза при обозначении мотивов его выбора. Очевидна ориентация на то, что здесь (в МосГУ) дают хорошее образование (64,7\% на фоне среднего показателя 49,1\%), создают возможности для трудоустройства (21,6 и 13,8\%), больше позитивных оценок умеренности платы за обручение $(32,4$ и $18,1 \%)$.

Трудности адаптации этой группы видятся в несформированности профессиональных ориентаций, что делает необходимыми мероприятия, направленные на профессиональную социализацию, которые исходили бы из самого начального ее уровня, которым характеризуются по крайней мере треть первокурсников.

Первокурсники, определившие непонятность изложения материала на занятиях и трудность отдельных предметов как основные сложности, с которыми уже пришлось столкнуться в учебном процессе (Группа В). Аналитически выделяется группа испытывающих уже на первых порах трудности понимания учебного материала. Эта группа (обозначенная в исследовании как «Группа В»), объединяет тех первокурсников, которые на вопрос о трудностях, с которыми им уже пришлось столкнуться отметили, что «материал на занятиях излагается преподавателями непонятно», и тех, кто посчитал, что им «трудно даются отдельные предметы». Первые составляют 8,9\% опрошенных, вторые 16,1\%, что в совокупности образует довольно внушительную группу: одну четвертую часть первокурсников $(25,0 \%)$.

Очевидны здесь проблемы довузовской подготовки и другие проблемы, связанные с развитием ментальных и иных личностных способностей и навыков, необходимых в учебе. Эти обстоятельства еще предстоит описать и осмыслить в психологических, педагогических и культурологических исследованиях первокурсников. Здесь же следует отметить некоторые отклонения ответов этой группы по частотности выбора от средних по контингенту первокурсников (таблица 20, с. 76).

В Группе В адаптационные трудности концентрируются вокруг вопросов учебы, отношений в однокурсниками, ослаблена мотивация обучения перспективами будущей профессиональной деятельности, отсюда - ориентация на работу после вуза лишь по признаку высокой ее оплаты, расчеты на второе высшее образование и намерения искать удачи за границей. Подобным же образом среди тех, кого настораживает требовательность преподавателей, в 3 раза больше тех, кто помышляет о заграничной жизни (75,0\% против 23,7\% в среднем по первокурсникам).

Возможно, предчувствия первокурсников, отнесенных к Группе В, что у них возникнут трудности с оплатой учебы в университете, отражают лишь то, что они не уверены в своей способности освоить учебную программу. В этом аспекте данная группа может создавать проблемы для сохранения контингента студентов МосГУ.

\section{ТЕОРЕТИЧЕСКИЙ АСПЕКТ УСТАНАВАИВАЕМЫХ ЭМПИРИЧЕСКИ ТРУАНОСТЕЙ АААПТАЦИИ ПЕРВОКУРСНИКОВ К УЧЕБЕ В ВУЗЕ}

Эмпирические факты относительно первокурсников, испытывающих трудности адаптации к учебе в гуманитарном вузе, позволяют сделать и некоторые теоретические выводы в области социологии молодежи.

Зададимся вопросами: 
ОТВЕТЫ НА ВОПРОСЫ АНКЕТЫ ПЕРВОКУРСНИКОВ, СЧИТАЮЩИХ,

Таблица 20 ЧТО МАТЕРИАА НА ЗАНЯТИЯХ ИЗААГАЕТСЯ ПРЕПОААВАТЕ ЕМ НЕПОНЯТНО И ПРИЗНАЮЩИХ, ЧТО ИМ ТРУАНО ААЮТСЯ ОТАЕАЬНЫЕ ПРЕАМЕТЫ (В \%)

\begin{tabular}{|c|c|c|}
\hline $\begin{array}{c}\text { Bonросы } \\
\text { и варианть ответов }\end{array}$ & Групnа B & $\begin{array}{c}\text { Средний } \\
\text { показатель }\end{array}$ \\
\hline \multicolumn{3}{|c|}{ Чего Вы опасаетесь больше Всего? } \\
\hline ухудшения материального положения (своего, своей семьи) & 58,3 & 39,8 \\
\hline \multicolumn{3}{|c|}{ Что Вас больше Всего настораживает в учебе и студ. жизни на территории МосГУ? } \\
\hline предстоящие экзамены, зачеты & 81,7 & 71,6 \\
\hline требования преподавателей & 10,5 & 3,7 \\
\hline сложности учебного материала & 7,8 & 5,5 \\
\hline сложные отношения с однокурсниками & 7,9 & 1,8 \\
\hline финансовые трудности оплаты обучения & & \\
\hline \multirow{2}{*}{\multicolumn{3}{|c|}{ Кто помогает Вам решать возникающие в прочессе обучения проблемь? }} \\
\hline & & \\
\hline сотрудники деканата, кафедр, администрация университета & 20,6 & 13,0 \\
\hline решаю сам(а) & 63,4 & 50,4 \\
\hline \multicolumn{3}{|c|}{ Каковы Ваши планы после окончания университета? } \\
\hline работать по специальности, полученной в МосГУ & 42,2 & 48,3 \\
\hline не по специальности & 26,7 & 22,0 \\
\hline найти высокооплачиваемую работу, даже если она будет & & \\
\hline не по специальности & 42,2 & 33,1 \\
\hline получить второе высшее образование & 36,1 & 30,5 \\
\hline уехать на работу за границу & 34,5 & 23,7 \\
\hline \multicolumn{3}{|c|}{ Что, по Вашему мнению, означает «хорошо жить»? } \\
\hline быть здоровым & 73,9 & 53,8 \\
\hline
\end{tabular}

1. Почему определенная часть молодежи, испытывающая подобные трудности нередко со школьных лет, все же идет в вузы?

2. Какого рода ожидания молодежи от гуманитарного вуза и влияют ли эти ожидания на формирование трех выделенных в эмпирическом исследовании проблемных групп?

3. Три выделенные группы отражают кластеризацию первокурсников, испытывающих трудности адаптации к учебе в гуманитарном вузе, или есть группы с неясными трудностями, ими самими не воспринимаемыми, но отражающими особенности социального и культурного статуса молодежи в нынешнем обществе?

4. Это - временные характеристики или они содержат в себе противоречия будущего?

Попробуем за эмпирическими данными одного вуза увидеть обобщенную картину, отраженную в этих вопросах.

Прежде всего, отметим применимость к такого рода обобщениям субъектно ориентированных теорий общества и соответствующих им методологий (Мамажаа, 2017), 
а более всего - тезаурусного подхода. Его концептуальное выражение состоит в том, что субъектная организация гуманитарного знания состоит в структурировании этого знания по оси «свой-чужой-чуждый» (Ауков В. А., Ауков Вл. А., 2008, 2013; Захаров, 2008). По этой же оси происходит и тезаурусное расширение (Ауков В. А., $\Lambda$ ков С. В., 2012), и становление культурных констант (Гайдин, 2011). Если исходить из тезаурусного подхода, в юности окончательно формируется культурная картина мира (Кузнецова, 2012; Погорский, 2012), которая не равна естественнонаучной картине мира и может складываться из фрагментов, которые сами по себе не составляют целого и принадлежат разным знаниевым системам, нередко фантазийным, но воспринимаемым субъектом как реальные. Здесь более чем уместна «теорема Томаса», как назвал ее видный американский социолог Р. Мертон: «Если люди определяют ситуации как реальные, то они реальны в своих последствиях» (Мертон, 2006: 605). У. Томас увидел в таком спутанном представлении о действительности реакцию психически больного человека на наличные обстоятельства и последующего влияния на них, реализация этого правила в приводимом им примере носила частный характер. Мертон из наблюдения Томаса вывел общую теорему, свойственную людям. Но ее надо более определенно применить к молодежи, особенно начинающей свой жизненный путь: в молодости фантазийное представление о реальности, смешение реальности и виртуальности присуще совершенно здоровым людям и отражает лишь недостаток жизненного опыта на фоне стремления к его (опыта) обновлению, «но, поди ж ты, - как говорил в одной из своих притч Ф. Кафка, - и это только кажется».

С учетом сказанного ответим на поставленные выше вопросы.

1. Само намерение идти в вуз не является молодежной идеей, оно отражает установившуюся в данном обществе социализационную траекторию (Ковалева, Богданова, 2012). Немалую роль играют родители и школа, которые принуждают молодого человека идти после школы в вуз, оставляя ему (но не всегда) право выбрать, в какой именно. То, что А. С. Пушкин или А. П. Чехов не имели в современном понимании высшего образования, а И. С. Тургенев или $\Lambda$. Н. Толстой - даже и среднего, что ныне обязательно должно предшествовать вузу, в типичной социализационной траектории, утвердившейся в России, неважно, как и то, что эти писатели не делали ошибок не только в русской, но и во французском и других языках, ведя нередко переписку с носителями языка на их родном наречии. Как показывают диктанты в вузах Москвы, ошибками в русском языке пестрят работы студентов - будущих журналистов даже в таких престижных вузах, как МГУ (Агранович, 2009. Электрон. ресурс). Различие именно в том, что некоторые молодежные статусы закрепились в обществе как желательные или в ряде случаев (например, при приеме на определенные должности) как обязательные. Образование групп первокурсников с трудностями адаптации к учебе в вузе, таким образом, неизбежное следствие получивший в конце XX - начале XXI в. социальных процессов (не только российских).

2. Ожидания молодежи от гуманитарного вуза в некоторой части связаны с тем, что естественнонаучные дисциплины воспринимаются в обществе как более трудные Аля освоения, что связано со школьной программой. Соответственно, достаточно распространено мнение, что в гуманитарном вузе учиться легче и что легче получить диплом о высшем образовании (будущая работа на начальном этапе в расчет не принимается). Эти ожидания мотивируют восприятие первокурсниками трудностей адаптации к гуманитарному вуза в выделяемых группах Б и В. 
3. Выделенные три группы отражают кластеризацию первокурсников, испытывающих трудности адаптации к учебе в гуманитарном вузе, на уровне видимых причин. Группа А, видимо, включает в себя тех, кому трудности учебы не ясны, напряженность может иметь и этот источник. Социологическое эмпирическое исследование не проясняет эту напряженность, поскольку имеет дело с сознанием (реакции на поставленные вопросы), а могут иметь место и бессознательные реакции, плохо понимаемые их носителями. В их числе могут быть и по-видимости немотивированные перемены настроения, в действительности отражающие черты социального и культурного статуса молодежи в обществе: могут иметь место этнонациональные особенности, освоенные формы воспитания, религиозные предпочтения и т. А. Подобное восприятие первокурсниками выдвигаемых требований как «дури» описано на материалах милицейских вузов. Характерно, что такие реакции исчезают к выпускным курсам (Ауков, Агранат, 2005).

4. Из предыдущего вытекает, что трудности, испытываемые первокурсниками на начальной этапе учебы в гуманитарном вузе, носят временный характер. В самом деле, они в основном исчезабт мо мере движения к выпускному курсу. Частью әто результат отсева или добровольного ухода студентов из вуза. Причины могут быть разные, определенная их часть заключается в невнимании вуза к возникающим уже в начале обучения проблемам первокурсников. Но нас интересуют здесь причины, позволяющие говорить о противоречиях будущего. Их (эти причины) можно разбить на две группы.

1. Ожидания студентов не соответствуют качеству обучения. Студенты сталкиваются с примитивным и устарелым представлением материала, имея возможность получать многое из электронных сетевых ресурсов (многое - не значит достоверное). Они сталкиваются и с ослаблением дисциплины, к которой привыкли в школе, с покладистостью преподавателей на зачетах и экзаменах, с тем, что этими открывшимися ресурсами успешно пользуются те, кто не заслуживает снисхождения в учебных делах. Это наиболее заметная и вербализуемая причина. Она со временем может и устраняться как вузом, так и системой студенческого самоуправления.

2. Более сложна для раскрытия та группа причин и, следовательно, носителей проблемы, которая связана с изменениями в природе человека и относится в биосоциологии молодежи (Ауков, 2013, 2015b; Колин, 2012). Еще не вполне ясно, как новые средства коммуникации, био- и медицинские технологии повлияют на подрастающие поколения. Система высшего образования так вопрос и не ставит, так что изменения, которые ощущаются ныне как некая неудовлетворенность первокурсников гуманитарных вузов, будет формироваться постепенно и параллельно процессам в высшем образовании. О явном противоречии мы узнаем позже, через 5-10 лет, когда будет уже поздно. Но пока эти предположения могут проверяться как относящиеся к области теоретических основ социологии молодежи.

\section{ЗАКАЮЧЕНИЕ}

Эмпирические исследования первокурсников важны прежде всего для вуза, на базе которого они проводятся. Аля понимания «своего» контингента обучающихся такие исследования и предназначены, здесь их прикладной характер наиболее заметен. Но косвенно они выявляют тенденции, которые пока только наметились в новых поколениях и могут реализоваться в будущем. В этом отношении эмпирические исследования по вузам дают определенный материал для социологии молодежи как активно 
развивающейся отрасли социологии. Трудные вопросы методики и техники таких исследований (тип выборки и т. А.) снимаются применением сплошного опроса, и хоть он скрывает некоторые методические неточности (не все студенты по разным причинам бывают на занятиях, которые используются для сплошного опроса), применительно к первокурсникам он надежнее выборочного метода и репрезентативен для вуза.

Аанное исследование показало, что могут быть определены номинативные группы первокурсников, которые испытывают трудности адаптации к учебе в гуманитарном вузе. Но оно скорее сигналит о проблемах: некоторые могут быть быстро решены усилиями педагогического состава, другие сами собой исчезнут по мере освоения первокурсниками принятых правил и того, что называется взрослением. Но некоторые проблемы не ясны ни вузу, ни носителям проблемы, они подобны бессознательному у 3. Фрейда: мы о нем знаем только по удовлетворенности или неудовлетворенности, которые испытывает человек в той или иной ситуации. Выявляемые несоответствия на эмпирическом уровне и оказываются стимулом к развитию социологии молодежи как определенной совокупности теоретических утверждений, которые меняются вслед за переменами в обществе.

\section{СПИСОК АИТЕРАТУРЫ}

Агранович, М. (2009) «Поциэнта» «оррестовали»: Первокурсники журфака МГу «завалили» установочный диктант [Электронный ресурс] // Российская газета. URL: https://rg.ru/ 2009/11/18/diktant-poln.html (дата обращения 17.08.2017).

Гайдин, Б. Н. (2011) Вечные образы как константы культуры: тезаурусный анализ «гамлетовского вопроса» : монография. Saarbrücken : Lambert Academic Publishing. 212 c.

Гневашева, В. А., Ауков, В. А. (2008) Первокурсник Московского гуманитарного университета: год 2007: результаты социол. исследования : мониторинг (этап 2007 г.). М. : Изд-во Моск. гуманит. ун-та. 46 с.

Захаров, Н. В. (2008) Шекспиризм русской классической литературы: тезаурусный анализ : монография / отв. ред. Вл. А. Ауков. М. : Изд-во Моск. гуманит. ун-та. 320 с.

Ковалева, А. И., Богданова, В. В. (2012) Траектория социализации : монография. М. : Изд-во Моск. гуманит. ун-та. 184 с.

Колин, К. К. (2012) Биосоциология молодежи и проблема интеллектуальной безопасности в информационном обществе // Знание. Понимание. Умение. № 3. С. 156-162.

Кузнецова, Т. Ф. (2012) Культурная картина мира: теоретические проблемы : науч. монография. М. : ГИТР. 250 с.

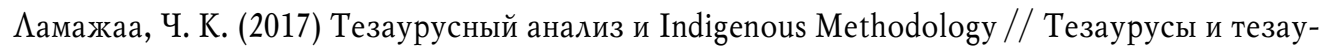
русная сфера : II Академические чтения памяти Владимира Андреевича Аукова, 29 марта 2017 г. : сб. науч. трудов. М. : Изд-во Моск. гуманит. ун-та. 256 с. С. 115-126.

Ауков, Вал. А. (2013) Биосоциология молодежи: теоретико-методологические основания : науч. монография. М. : Изд-во Моск. гуманит. ун-та. 430 с.

Ауков, В. А. (2015а) Каков он - первокурсник факультета рекламы // Вестник Московского гуманитарного университета. № 2. С. 14-16.

Иуков, В. А. (2015b) Биосоциология: ресурс понимания молодого поколения России // Стратегические приоритеты. № 1(5). С. 72-83.

Ауков, В. А., Агранат, А. А. (2005) Курсанты: Плац. Быт. Секс: Социологическое и социально-психологическое исследование : монография. М. : Флинта : Наука. 272 с.

Ауков, В. А., Гневашева, В. А., Ковалева, А. И., Ауков, С. В. (2006) Первокурсник Московского гуманитарного университета: год 2006: По материалам социологического исследования (мониторинг, этап III). М. 39 с.

Ауков, В. А., Ауков, Вл. А. (2008) Тезаурусы : Субъектная организация гуманитарного знания. М. : ИзА-во Нац. ин-та бизнеса. 784 с. 
Ауков, В. А., Ауков, Вл. А. (2013) Тезаурусы II : Тезаурусный подход к пониманию человека и его мира : монография. М. : Изд-во Нац. ин-та бизнеса. 640 с.

Ауков, В. А., Ауков, С. В. (2012) Принцип тезаурусного расширения индивидуального межкультурного пространства // Тезаурусный анализ мировой культуры : сб. науч. трудов. Вып. 23 / под общ. ред. Вл. А. Аукова. М. : Изд-во Моск. гуманит. ун-та, 2012. С. 10-21.

Мертон, Р. (2006) Социальная теория и социальная структура: пер. с англ. М. : АСТ: АСТ Москва: Хранитель. 873 с.

Первокурсник Московского гуманитарного университета: 2004 год: Итоги междисциплинарного исследования (2005а). Ч. 1 / под общ. ред. Вал. А. Аукова, А. И. Ковалевой. М. : Изд-во Моск. гуманит. ун-та. 100 с.

Первокурсник Московского гуманитарного университета: 2004 год : Итоги междисциплинарного исследования (2005b). Ч. 2 / под общ. ред. Вал. А. Аукова, А. И. Ковалевой. М. : Изд-во Моск. гуманит. ун-та. 32 с.

Погорский, Э. К. (2012) Картина мира // Знание. Понимание. Умение. № 4. С. 322-323.

Аата поступления: 18.08.2017 2.

Иуков Валерий Андреевич - доктор философских наук, профессор, директор Института фундаментальных и прикладных исследований Московского гуманитарного университета, заслуженный деятель науки Российской Федерации, академик Международной академии наук (IAS, Инсбрук). Адрес: 111395, Россия, г. Москва, ул. Юности, д. 5. Тел.: +7 (499) 374-75-95. Эл. aApec: v-lukov@list.ru

Lukov Valery Andreevich, Doctor of Philosophy, Professor, Director, Institute of Fundamental and Applied Studies, Moscow University for the Humanities; Honored Scientist of the Russian Federation, full member of the International Academy of Science (Innsbruck). Postal address: 5 Yunosti St., Moscow, Russian Federation 111395. Tel.: +7 (499) 374-75-95. E-mail: v-lukov@list.ru

Ауков Сергей Валерьевич - кандидат социологических наук, магистр социальной работы (Германия), начальник отдела прикладной социологии Центра социологии молодежи Института фундаментальных и прикладных исследований Московского гуманитарного университета. Адрес: 111395, Россия, г. Москва, ул. Юности, А. 5. Тел.: +7 (499) 374-75-95. Эл. адрес: svlukov@mail.ru

Lukov Sergey Valerievich, Candidate of Sociology, Master of Social Work (Germany), Head, Department of Applied Sociology, Centre for Sociology of Youth, Institute of Fundamental and Applied Studies, Moscow University for the Humanities. Postal address: 5 Yunosti St., Moscow, Russian Federation 111395. Tel.: +7 (499) 374-75-95.E-mail: sv-lukov@mail.ru

Аля ичитирования:

Ауков В. А., Ауков С. В. Адаптация к учебе в вузе отдельных проблемных групп первокурсников: эмпирические данные и теоретические выводы [Электронный ресурс] // Горизонты гуманитарного знания. 2017, №5. URL: http://journals. mosgu.ru/ggz/article/view/604 (дата обращения: АА.мм.гггг.). DOI: 10.17805/ggz.2017.5.7 